\title{
Invasion, colonization, and disturbance; historical ecology of the endangered Miami blue butterfly
}

\author{
Scott P. Carroll* and Jenella Loye \\ Department of Entomology, University of California, Davis, CA 95616, USA and Carroll-Loye Biological \\ Research, 711 Oak Avenue, Davis, CA 95616,USA; *Author for correspondence (e-mail: spcarroll@ucda- \\ vis.edu; phone: +1-530-297-6080; fax: +1-530-297-6080)
}

Received 25 January 2005; accepted in revised form 2 June 2005

Key words: Cardiospermum, Chlorostrymon, Conservation, Florida Keys, Cyclargus thomasi, Hemiargus, Invasion, Jadera, Lisseurytomella, Mosquito Control, Soapberry bug

\begin{abstract}
The Miami blue butterfly, Cyclargus thomasi bethunebakeri (Lycaenidae), which was widespread in coastal southern Florida in the last century, is now reduced to a few dozen individuals on a single islet of the Florida Keys. We present the first account of its reproductive ecology, and analyze its decline. We correct the common view that a principal host plant, balloon vine, is an exotic weed. Four other insects also feed on seeds of balloon vine, including a true bug, a wasp, and another lycaenid hairstreak that colonized the area in 1970. Larvae of the two lycaenids were negatively associated across sites, due in part to oviposition decisions. Balloon vines were more likely to abort fruit containing larval blues than hairstreaks. Most focal host plants disappeared between 1988 and 2003, mainly due to human disturbance. In addition, comparative evidence suggests that the blue and wasp were more susceptible to mosquito control spraying than were the other insects.
\end{abstract}

\section{Introduction}

Among the threatened taxa of South Florida, the Miami blue, Cyclargus (formerly Hemiargus) thomasi bethunebakeri, has received special attention. Community activism led to its listing as an endangered species through a rarely used emergency action in January 2003 (Florida Fish and Wildlife Conservation Commission 2003). Formerly found in coastal regions of southern Florida, by the 1980s it was limited to a few sites in the Florida Keys (Calhoun et al. 2002). Hurricane Andrew destroyed the last known colony from that era, on Key Biscayne, in 1992. No additional sightings were made for seven years, until rediscovery of the species on Bahia Honda Key in late 1999 (Calhoun et al. 2002).
Coastal southern Florida supports an 'Antillean' biotic community descended mainly from closely related Caribbean populations, and limited within the continental US to this peripheral zone (Tomlinson 1980). The modest geographic extent of the Florida Keys archipelago ('Key', like 'Caye', meaning island), high species diversity and great distances to related populations imply that many constituent species will exist as small populations. Such populations may be at inherently greater risk of extinction (Diamond 1984), and this circumstance appears to commonly afflict host-specialized lycaenid butterflies such as the Miami blue (papers in New 1997).

In the Florida Keys, habitat limitation has been exacerbated by human disturbance. Broad-scale forest clearing for plantation agriculture began 
more than 100 years ago (Minno and Emmel 1993), and contemporary urban and suburban development has reduced the original upland habitat by $50 \%$, with approximately 10,000 acres remaining (Monroe County 2002). Naturally fragmented among islands, such development has further reduced patch size, increased distances among patches, and created barriers to dispersal (Strong and Bancroft 1994). Recognizing their importance and fragility, the Keys as a whole were designated as an 'Area of Critical State Concern' three decades ago (Florida Administrative Code 1975). Remnant terrestrial habitats are now receiving increased protection, and land use and development are more regulated (Monroe County 1995).

Little is known about the biology of the Miami blue and its biotic associates on which to base a conservation plan. Current work is compromised by the species' vulnerable status, but here we provide information on its behavior and reproductive biology collected in the Upper Florida Keys in 1988, 1989 and 2003 that may contribute to such a basis. The data from the 1980s were collected in tandem with studies otherwise focused on a non-threatened hemipteran seed predator that shares the same host plant. Hence our most detailed observations for the Miami blue involve egg-laying and larval behavior rather than observations of adults away from host plants. At that time the blue was common in the area; the goal of our return in 2003 was to search for clues to explain its demise.

\section{Background}

Cyclargus thomasi is a West Indian blue with six geographic subspecies within the region extending from southern Florida and the Bahamas to the Turks and Caicos, as well as the Greater Antilles to the northern Lesser Antilles (Smith et al. 1994). Bright blue above and grayish below, it has a wingspan of about $2.5 \mathrm{~cm}$. C. thomasi bethunebakeri is the race restricted to southern Florida; it has also been reported from Bimini but its status there is not well documented (Smith et al. 1994). Larval diet of the various races consists of developing seeds of balloon vines, Cardiospermum spp. (Sapindaceae) as well as meristematic tissue of leguminous shrubs and trees (Caesalpinia and Pithecellobium) (Smith et al. 1994, p. 129). The Miami blue has been reported from all three of these host genera (Minno and Emmel 1993; Calhoun et al. 2002).

Until recently balloon vine was the principal host of the Miami blue (Opler and Krizek 1984; Smith et al. 1994). The current population has no access to this host (which is now restricted mainly to the Upper Keys; Figure 1), and feeds instead on Caesalpinia bonduc, or nickerbean. In most species of balloon vine the fruit is an inflated, thin-walled spherical capsule about $3 \mathrm{~cm}$ in diameter. Three species of Cardiospermum occur in southern Florida: the cosmopolitan annual or biannual herbaceous weed, Cardiospermum halicacabum (heart seed vine), the large, woody, native perennial balloon vine, $C$. corindum, and the widespread, herbaceous and weedy $C$. microcarpum (Wunderlin 1998). This last species lacks an inflated capsule and has not been reported as a host of the Miami Blue. Cardiospermum corindum fruits year round (Carroll et al. 2003).

The identity of the Cardiospermum host is in question. All published reports of Miami blue larvae on this genus have identified the host as C. halicacabum (Lenczewski 1980; Leston et al. 1982; Minno and Emmel 1993; Smith et al. 1994; Calhoun et al. 2002), with the exception of Carroll and Loye (1987). However, large, woody individuals are predominant among the reproductively active balloon vines in the Upper Keys (Carroll and Loye 1987; Carroll et al. 2003, Loye and Carroll, in press) with reproductive characters keyable to C. corindum (e.g., Wunderlin 1998). Accurately identifying the species is especially important because $C$. corindum in southern Florida may be locally differentiated from other populations (Small 1933), and because, in contrast, the weedy $C$. halicacabum is an agricultural pest with eradication programs in other southeastern US states. In addition, the long-term success of proposed reintroduction of captive-reared blues throughout the Keys (Emmel and Daniels 2003) may be enhanced by knowledge of its biology in relation to the balloon vine host.

Decades of fragmentation have created substantial forest edge areas along roadsides that may place insects at risk. While balloon vine appears to grow well along roads, such edges may also be less moderated against certain environmental stressors and disturbance. A chief candidate for stress to the insect community is periodic spraying of insecti- 


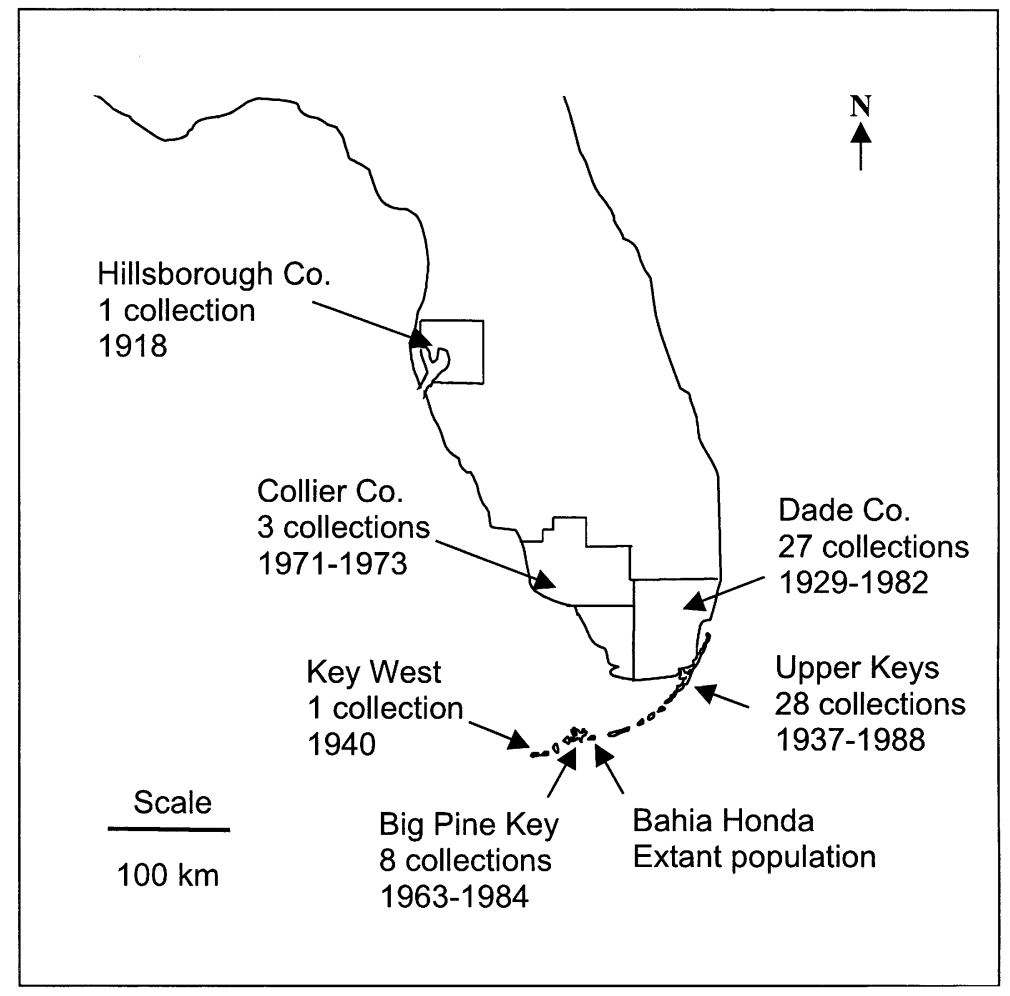

Figure 1. Miami blue: spatial and temporal patterns of historical collection events in Florida, designated by county or other geographic region. For the Florida Keys archipelago, text references to the 'Upper Keys' refer to the northernmost group of islands (contiguous in this figure); the 'Lower Keys' are the southernmost group, including Big Pine Key. The islands between these two groups are the 'Middle Keys', which include the island of Bahia Honda, locale of the extant population of the butterfly.

cides for adult mosquito control from truckmounted foggers. The principal insecticide used in fogging during the period of this study, and continuing until August 1994, was malathion in a diesel fuel carrier (M. Spoto, Florida Keys Mosquito Control District (FKMCD), pers. comm. 2003).

Four other seed predators also use balloon vine in the Keys, including another lycaenid butterfly, a tortricid moth, a true bug and a wasp. Within this guild we focused on the lycaenids and the wasp, which forage for the same resource, immature seeds. The bug, in contrast, feeds on mature seeds and is comparatively well studied (e.g. Carroll et al. 1998); the moth was very rare. The second butterfly, the silver-banded hairstreak (Chlorostrymon simaethis), emigrated from the Caribbean beginning in 1970 (Fisher 1974, 1975). We are particularly interested in the possibility that this species has impacted the blue.

\section{Methods}

\section{Museum data sets}

To map historical changes in the range and density of the Miami blue we examined the specimens in the Florida State Arthropod Collection in Gainesville and the Allyn Museum in Sarasota. Older specimens of C. thomasi in the State collection were sometimes mislabeled as Hemiargus ammon, a designation unrelated to the recent colonization of the lower Keys by true members of that species (Calhoun et al. 2002). From each specimen we recorded the collection date, location, identity of the collector, and host (rare). We defined a collection event as consisting of all specimens taken by an individual or team from a single locale within a one-week period.

Likewise we used data from herbarium collections to map historical changes in the ranges of 
balloon vines. All specimens in the genus Cardiospermum were examined in herbaria of the University of Florida, the University of South Florida, and Fairchild Tropical Gardens (FTG). From each specimen we recorded species, collection date, location, identity of the collector, and any additional information provided (e.g., habitat).

\section{Field studies of balloon vines}

We searched for balloon vine on the Upper, Middle and Lower Florida Keys in 1985, 1988, 1989, and 2003. Hammock (forest) edges along roads and trails were inspected, with particular attention to Key Largo (northern and ocean side), Plantation Key and Big Pine Key (Watson's Hammock reserve, Cactus Hammock Reserve and roadside hammock edges) due to their extensive upland habitat. In 2003, we employed low altitude helicopter surveys to search for hammock areas potentially overlooked in previous ground-based investigations. This led to additional ground searches on Big Pine Key, No Name Key, and Cudjoe Key.

We monitored reproductive balloon vines for fruit production and seed predators. Thirty-two vines were studied on Plantation Key in 1988-1989. These vines were arrayed along a roadside bordering secondary forest, a minimum of $30 \mathrm{~m}$ apart, and distributed over approximately four linear kilometers. In March 2003, we conducted a new survey with two additional aims. First, we assessed the conditions of individual vines known from 1988-1989, and documented agents of disturbance during the intervening years, including road maintenance and construction. New vines within $10 \mathrm{~m}$ of an original plant were assumed descended from that plant. Second, we included 40 additional vines on Plantation Key and Key Largo. We recorded the maximal stem length, woodiness, maximum stem diameter, condition and reproductive status of all vines. Fruits are termed 'capsules' or 'balloons'.

\section{Field observations of insects}

We identified adult butterflies to species by consultation with T. Emmel (McGuire Center, University of Florida) and by reference to identified specimens in the Florida State Arthropod
Collection in Gainesville. By observing oviposition we were able to identify butterfly eggs to species. We compared the distribution of eggs among fruit within and between the species with Fisher's Exact Probability tests.

By rearing larvae to maturity we were able to identify characters that distinguished caterpillars to species after they were about $1 / 2$ maximal length. To sample such larvae we inspected the interiors capsules by carefully tearing ca. $1.5 \mathrm{~cm}$ openings along valve seams. Fallen capsules were also opened, and fallen or attached capsules were sometimes removed temporarily to a laboratory setting. Similarly, we monitored the activity of larval Eulophid wasps based on characteristic galling of the seeds. We sampled adult wasps as they emerged within capsules, and sexed them on the basis of body size, antennal characters and the presence or absence of an ovipositor.

We conducted larval surveys to describe each insect species' phenology of host use, patterns of co-occurrence (Spearman rank correlations), and impact on the seed crop of the host plant. Occupancy of insects was recorded by individual plant and date. We also made general observations on pupation behavior and the relationships between the butterflies and attendant ants.

To assess possible effects of insecticidal spraying for mosquitoes on the insects associated with balloon vine, we compared samples of the insects between sites exposed to vs. protected from truckbased roadside fogging. Exposed sites were defined a priori as those within $10 \mathrm{~m}$ of an active roadway, in contrast to protected sites, defined as those more than $50 \mathrm{~m}$ distant from an active roadway.

\section{Studies with captive insects}

We studied larval butterfly development and feeding in the laboratory (mean daytime temperature $26 \pm 2{ }^{\circ} \mathrm{C}$, nighttime $20 \pm 2{ }^{\circ} \mathrm{C}, \quad \mathrm{L}: \mathrm{D}$ ca. 12:12). Larvae were collected within capsules and held individually in $4 \times 3 \times 2 \mathrm{~cm}$ clear plastic boxes. Each larva was supplied with full-sized, green, field-collected seeds daily. Because we collected most larvae after the time of hatching, we estimated development times on the basis of time to pupation for those collected at lengths of $1-4,5-8$, and $9-11 \mathrm{~mm}$. We compared these times, and 
pupal stage duration, between the two species with Wilcoxon Rank-sum tests. We also recorded the number of seeds ingested by each larva during development. Once they matured, we released all captive subjects at their collection sites.

\section{Capsule abortion and seed predation}

We related rates of seed capsule abortion to the presence of seed predators, and compared rates between each butterfly and the wasp with goodness-of-fit tests. To mimic damage to the capsule wall from foraging caterpillars we cut $1.5 \mathrm{~mm}$ holes in intact mature and immature fruits at four plants, which we left intact or immediately sealed with a minimal application of clear nail polish. Rates of abortion of capsules so treated, as well as those of untreated sibling capsules, were measured at one week after treatment. All plants were tented with lightweight netting to exclude seed predators throughout the experiment.

\section{Results}

Which Cardiospermum? Taxonomic identity of the principal historic host plant

Both C. corindum and C. halicacabum are present in the southern-most regions of the state. All but one of 44 Florida herbarium specimens of C. corindum were from this region, as were nine of 16 specimens of $C$. halicacabum. In the field most or all plants in the Upper Keys were perennial, and thus like C. corindum rather than C. halicacabum. Of 15 reproductive individuals marked in 1988, all were present 13 months later in 1989. One of these individuals was still extant in 2003. Of 87 individuals classed for basal stem woodiness during 2003, 38 were woody (mean \pm sd stem diameter $13.8 \pm 8.1 \mathrm{~mm}, N=26)$ and 49 were not $(2.6 \pm$ $1.3 \mathrm{~mm}, N=10$ ). Ninety percent (34) of woody plants had stem lengths greater than $5 \mathrm{~m}$, while none of the nonwoody plants did. We found no systematic differences in flower, fruit, aril size or fruit shape characteristics between woody and nonwoody individuals.

To distinguish whether these smaller, nonwoody individuals were likely to be young $C$. corindum rather than mature $C$. halicacabum, we checked for presence of fruits or flowers. Only $12 \%(N=6)$ of nonwoody plants were reproductive, in contrast to $66 \%$ of woody plants. Seedlings were present around 10 of 38 woody individuals, while none were noted around any nonwoody individuals as large or larger than the six reproductive nonwoody individuals $(N=12)$.

These results suggest that many nonwoody individuals were young $C$. corindum. Due to the preponderance of plants assignable to C. corindum, all instances of the term 'balloon vine' in the remainder of the paper refer to that species.

\section{Present and historical range of balloon vine}

Herbarium specimens showed that $C$. corindum ranged in the last century from northern peninsular Florida to Key West, and that it is now mainly limited to the Upper Florida Keys. Of the 44 specimens examined, 38 were from Old Rhodes Key to Upper Matecumbe Key (with four of these from the adjacent mainland); the plant is also on nearby Key Biscayne (T. Emmel, pers. comm.)). Collection dates for these specimens ranged from 1896 to 1998. Four specimens were from the northernmost Middle Keys (Lower Matecumbe Key, 1929-1966) and the final single specimen was collected in the extreme Lower Keys (Key West, 1941). We found no balloon vines to the south of Upper Matecumbe Key in either the 1980s or 2003.

\section{Present and historical range of Miami blue}

We compiled data on the collection locales of 209 specimens of adult Miami blues. These records indicate that the butterfly's range formerly extended from Hillsborough and Volusia counties in coastal north-central Florida through the entirety of the Florida Keys (Figure 1). Most specimens were from the Upper Keys (Table 1), and collections from more peripheral sites tended to be less recent and to consist of only single specimens. Notably, the eight specimens from Big Pine Key came from eight independent collection events over 21 years. In contrast, the 28 collections taken over 51 years in the Upper Keys had more than five times more specimens on average than did those from most peripheral sites (Table 1). 
Table 1. Specimen density per collection of Miami blue butterflies in the Allyn Museum and the Florida State Arthropod Collection $^{\mathrm{a}}$.

\begin{tabular}{lcll}
\hline Locale & $\begin{array}{l}\text { Number } \\
\text { of } \\
\text { specimens }\end{array}$ & $\begin{array}{l}\text { Number } \\
\text { of } \\
\text { collections }\end{array}$ & $\begin{array}{l}\text { Mean } \\
\text { specimens } \\
\text { per collection }\end{array}$ \\
\hline Collier County & 6 & 3 & 2 \\
Dade County & 37 & 27 & 1.4 \\
Hillsborough County & 2 & 1 & 2 \\
Monroe County & & & \\
Big Pine Key & 8 & 8 & 1 \\
Everglades & 1 & 1 & 1 \\
Key West & 1 & 1 & 1 \\
Upper Keys & 151 & 28 & 5.4 \\
\hline
\end{tabular}

${ }^{\mathrm{a}}$ Three specimens were not assignable.

${ }^{\mathrm{b}}$ Key Largo and Plantation Key.

\section{Incidence of seed predators, late 1980s}

The data presented in this and the next section are exclusively from 'protected' sites (at least $50 \mathrm{~m}$ removed from trafficked roadways). Data from 'exposed' sites (within $10 \mathrm{~m}$ of such roadways) are presented subsequently.

The four common seed predators were two lycaenid butterflies, a true bug, and a wasp (Table 2). The tortricid moth was observed on just five occasions. The other predators are obligatory or nearly so and were often observed together on the same individual host plants during JanuaryMarch 1988 and 1989.

Soapberry bugs were present at most sites on most days (totaling $86 \%$ of records), but the other species were less frequent and more variable. Infestation rates on green seeds within capsules were calculated for each lycaenid and the wasp. A total of 1216 capsules were examined in 1988, and 698 in 1989 (Table 3). The Miami blue was the most common of the insects that develop within the capsules, maximally occupying $40-50 \%$ of fruit in four of the twelve 1988 samples. Occurrences of the silver-banded hairstreak and the wasp were similar to one another in 1988. In 1989, a drought year, all of these predators were less common, and the wasp was absent. When all predators were present, a sizable portion of developing fruit was attacked (59\% of capsules inspected in 1988, Table 3). In addition, we found that soapberry bugs ate an average of $93 \pm 5 \%$ of mature seeds beneath seven focal vines.

Only 30 of the total of 1914 immature balloons examined contained more than one of the capsuledwelling species. Twenty of these contained a single Miami blue larva with wasp larvae or pupae, and ten contained a single Miami blue larva and a single silver-banded hairstreak larva. Wasps and hairstreaks were never observed together. Because of the potential for direct interaction among the seed predators, we compared the prevalence of each within sites. Figure $2 \mathrm{a}$ compares the incidence of the two butterflies in the 19 samples at protected sites in 1988 and 1989. Only when one butterfly was rare was the other common (Spearman $r=-0.65, p<0.0035)$. Similarly, infestation by wasps was rare when the hairstreak was common (Figure 2b; Spearman $r=-0.47$, $p<0.05)$. In contrast, incidence of the Miami blue and the wasp was positively correlated (Figure 2c; Spearman $r=0.62, p<0.006)$.

\section{Oviposition patterns within and among species}

In neither lycaenid were individual females observed to lay more than one egg on or near a particular fruit. Nonetheless, 24 of 54 capsules with $C$. thomasi eggs attached had more than one egg. Multiple ovipositions were less common in

Table 2. Seed predators of the balloon vine, Cardiospermum corindum, in the Upper Florida Keys.

\begin{tabular}{|c|c|c|c|c|}
\hline \multirow[t]{2}{*}{ Order } & \multirow[t]{2}{*}{ Predator (family) } & \multirow[t]{2}{*}{ Common name } & \multicolumn{2}{|l|}{ Presence } \\
\hline & & & 1988-1989 & 2003 \\
\hline Lepidoptera & Cyclargus thomasi (Lycaenidae) & Miami blue & Yes & No \\
\hline Lepidoptera & Chlorostrymon simaethis (Lycaenidae) & Silver-banded hairstreak & Yes & Yes \\
\hline Lepidoptera & Gonocausta sabinalis (Tortricidae) & None & Yes & Yes \\
\hline Hemiptera & Jadera haematoloma (Rhopalidae) & Soapberry bug & Yes & Yes \\
\hline Hymenoptera & Lisseurytomella flava (Eulophidae) & None & Yes & No \\
\hline
\end{tabular}


Table 3. Infestation of developing balloon vine seeds by the Miami blue, the silver-banded hairstreak, and a Eulophid wasp.

\begin{tabular}{|c|c|c|c|c|c|c|}
\hline \multirow[t]{2}{*}{ Year } & \multirow{2}{*}{$\begin{array}{l}\text { Total balloons } \\
\text { examined }\end{array}$} & \multicolumn{5}{|l|}{$\operatorname{Mean}( \pm \mathrm{sd})$} \\
\hline & & $\begin{array}{l}\text { Balloons per site } \\
\text { visit }\end{array}$ & $\begin{array}{l}\% \text { With } \\
\text { C. thomasi }\end{array}$ & $\begin{array}{l}\% \text { With } \\
\text { C. simaethis }\end{array}$ & $\begin{array}{l}\% \text { With } \\
\text { L. flava }\end{array}$ & Total $\%$ infested \\
\hline 1988 & 1216 & $101 \pm 50$ & $19 \pm 20$ & $11 \pm 13$ & $12 \pm 17$ & $59 \pm 24^{\mathrm{a}}$ \\
\hline 1989 & 698 & $100 \pm 60$ & $9 \pm 12$ & $4 \pm 2$ & 0 & $13 \pm 10$ \\
\hline
\end{tabular}

All values are from 'protected' sites; see text for explanation.

${ }^{a}$ Includes values of where damage was by one of the two lycaenids, but the species was undetermined.

C. simaethis: only 10 of 62 had more than one egg (between species, Fisher's exact two-tailed $p=0.005)$. An additional five of the 116 total capsules each had one egg from each butterfly species. This rate of overlap is considerably higher than that of interspecific co-habitation between the lycaenid larvae (10 of 1914, above).

Co-habitation was relatively more frequent between the Miami blue and the wasp. In this case, we found little indication of oviposition discrimination by the blues against sites occupied by wasps. For example, at one site on north Key Largo (February 1988), of 23 occupied fruits, 6 $(26 \%)$ had wasps and an unhatched blue egg, 10 $(44 \%)$ had a caterpillar plus an unhatched blue egg, and the remaining 7 (30\%) simply a single egg. In an additional 91 capsules sampled at the same place and time, but for which egg presence was not recorded, $71(74 \%)$ housed larval seed predators. Forty-one $(58 \%)$ of infested capsules contained only the Miami blue, 23 (33\%) only wasps, and $7(10 \%)$ both the blue and the wasp.

\section{Larval development}

In comparison to the silver-banded hairstreak, the Miami blue had a longer caterpillar stage, followed by a briefer pupal period (Table 4). Pupal size (length) did not differ between the species or sexes. We had few data on development from the egg stage, so we divided larvae into body length categories at the time of collection (Table 4). Comparing the number of days until pupation for each of these classes shows that the species difference expanded by about $0.6 \mathrm{~mm} /$ day from each larger class to each smaller class. From this we computed an estimated egg to pupation duration for $C$. simaethis of approximately 17 days, or about 2.5 days shorter than that of $C$. thomasi. Doing so yields an estimated total juvenile period duration of approximately 30 days, like $C$. thomasi. At minimum, the blue required $14 \%$ longer to develop during the bulk of the larval period, and its subsequent metamorphosis was $14 \%$ briefer.

Larval hairstreaks consumed more seeds as larvae than did Miami blues. By the time larvae collected in the smallest size class pupated, they had eaten, on average, $4.5 \pm 1.4$ seeds, while those of the blue ate $3.9 \pm 1.4$. These 17 hairstreaks ate an average of $0.39 \pm 0.15$ seeds/day, about $25 \%$ more than the 28 blues' average of $0.30 \pm 0.12$ (Wilcoxon $z=2.09, p<0.04$ ). Likewise, the average seed consumption of 10 midsize hairstreaks was $3.6 \pm 0.7(0.44 \pm 0.18 /$ day $)$, greater than the five blues' $2.8 \pm 1.6 \quad(0.26 \pm 0.01 /$ day $)$ (Wilcoxon $z=2.42, p<0.02$ ). Feeding rate in the largest larval size class was somewhat higher in the Miami blue, but not significantly so. The three larval blues that were monitored from hatching ate a mean of $6.7 \pm 1.5$ total seeds. Further, large $(11 \mathrm{~mm})$ larvae of both the blue and hairstreak may ingest an entire seed in a 1-day period $(\mathrm{N}=2$ and 5, respectively).

Because balloon vine capsules never contain more than three seeds, larvae of both species must forage beyond the natal capsule to complete development. They departed spent capsules by chewing a ca. $2 \mathrm{~mm}$ oblong opening and crawling through. A similar hole was chewed for entry into the wall of a second capsule, and the larva entered. In the Miami blue, attending Campanotus sp. also used this entry hole (11 of 200 capsules with larvae). In contrast, larval hairstreaks sealed entrance holes with silk, precluding the possibility of ant attendance. 

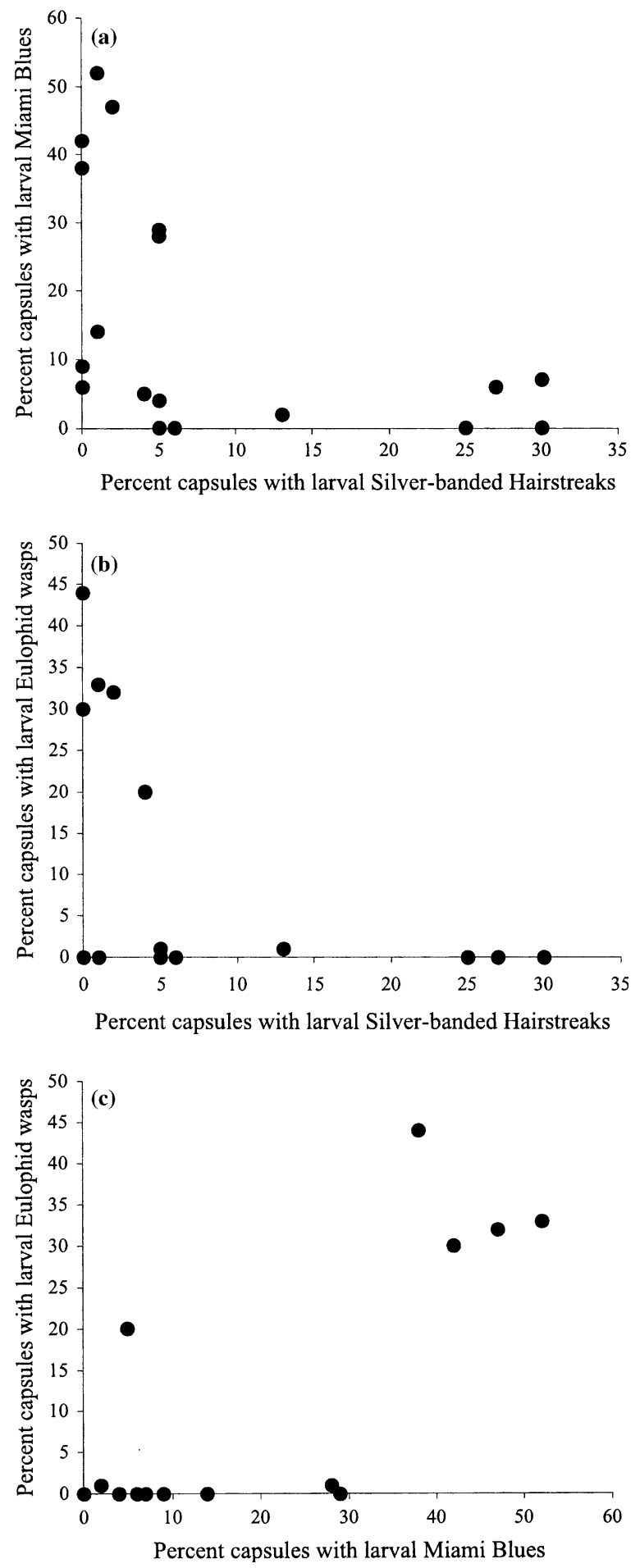

Figure 2. Patterns of negative and positive coincidence among the three species feeding as larvae on developing seeds within balloon vine capsules. (a) The silver-banded hairstreak and the Miami blue. (b) The silver-banded hairstreak and the Eulophid wasp. (c) The Miami blue and the wasp.
Miami blues frequently pupated within mature capsules attached to hosts, sometimes with Campanotus sp. ants in attendance (three of 20 capsules with pupae). Hairstreak pupae were more commonly found on the ground immediately beneath host plants. When placed with captive larval or pupal $C$. simaethis, Campanotus ants ignored them. In contrast, captive ants palpated C. thomasi larvae and pupae. Ants held with a succession of C. thomasi larvae lived for up to 23 days (end of experiment) with no supplemental materials, while those held with $\mathrm{C}$. simaethis or in isolation died within 3 days $(N=10$ per treatment).

Adult L. flava wasps were tiny (ca. $1 \mathrm{~mm}$ in length) and we observed them rarely, only during oviposition. Eggs were laid through the walls of immature fruits in the period between fertilization and inflation of the capsule. Unlike the butterflies, larval wasp dwelled within the developing seeds. Attacked seeds become enlarged, tuberculated, and changed from green to a bronzy yellow. As many as 35 adults emerged in a single balloon. The sex ratio was female-biased in all capsules (Table 5). In 46 wasp-bearing capsules collected from two sites in North Key Largo in January and February 1988, $373(88 \%)$ of 424 adults were female.

\section{Fruit abortion in relation to seed predation}

Balloons vines often aborted capsules containing larvae. Table 6 shows the infestation rates for four plants, comparing capsules still attached vs. those dropped to the ground during the previous $48 \mathrm{~h}$. The rate of infestation in aborted capsules at hairstreak-dominated sites averaged 3.7 times lower than that of attached capsules, while that at Miami blue sites averaged 2.1 times higher. With wasps, the contrast was even more extreme: the galling-like response was coupled with an absence of abortion.

Capsules with immature seeds were especially sensitive to experimental piercing of the capsule wall, averaging $90 \%$ abortion (Table 7 ). Sealing the artificial holes reduced abortion to $26 \%$, but this rate was still greater than in the untreated control $(9.5 \%)$. Mature capsules were less prone to drop than immature capsules whether treated or untreated. Again, however, sealing significantly reduced the probability of abortion. 
Table 4. Size (mm) and development time (d) attributes for larval C. thomasi and C. simaethis.

\begin{tabular}{|c|c|c|c|c|c|c|c|}
\hline \multirow[t]{2}{*}{ Species } & \multirow[t]{2}{*}{ Pupal length } & \multicolumn{4}{|c|}{ Days to pupation by initial larval stage ${ }^{a}$} & \multirow[t]{2}{*}{ Pupation duration } & \multirow[t]{2}{*}{ Juvenile period $^{\mathrm{b}}$} \\
\hline & & Egg & $1-4$ & $5-8$ & $9-11$ & & \\
\hline C. thomasi & $7.82(51)$ & $19.7 \pm 1.2(3)$ & $\begin{array}{l}13.5 \pm 2.6(28) \\
* *\end{array}$ & $10.2 \pm 3.2(5)$ & $7.3 \pm 1.4(13)$ & $\begin{array}{l}10.8 \pm 2.5(51) \\
* * *\end{array}$ & 30 \\
\hline C.simaethis & $7.72(36)$ & $17^{\mathrm{c}}$ & $11.8 \pm 2.4(17)$ & $9.0 \pm 2.5(14)$ & $6.7 \pm 2.9(7)$ & $12.5 \pm 2.2(55)$ & 30 \\
\hline
\end{tabular}

Sexes did not differ within species and are pooled. Values are means \pm standard deviations $(N)$.

${ }^{a}$ Numerical larval stages are larval body lengths at the time of collection.

${ }^{\mathrm{b}}$ Approximate days to pupation from egg plus pupation duration.

${ }^{\mathrm{c}}$ Estimated, see text.

**Species differ at $p<0.01$, Wilcoxon $z=2.63$.

$* * *$ Species differ at $p<0.001$, Wilcoxon $z=3.72$.

Table 5. Numbers of newly emerged male and female Lisseurytotnella flava wasps within individual balloon vine fruits.

\begin{tabular}{llll}
\hline $\begin{array}{l}\text { Males } \\
\text { in capsule }\end{array}$ & $\begin{array}{l}\text { Mean }( \pm \mathrm{sd}) \\
\text { females in capsule }\end{array}$ & Range & $\begin{array}{l}N \\
\text { occurrences }\end{array}$ \\
\hline 0 & $4.4 \pm 4.9$ & $1-19$ & 21 \\
1 & $8.2 \pm 5.7$ & $1-21$ & 14 \\
2 & $7.7 \pm 2.1$ & $6-10$ & 3 \\
3 & $16.0 \pm 4.4$ & $5-25$ & 4 \\
4 & $18.0 \pm 0.0$ & - & 2 \\
5 & 14 & - & 1 \\
6 & 29 & - & 1 \\
\hline
\end{tabular}

Table 6. Lycaenid and wasp infestation rates for attached vs aborted balloon vine capsules.

\begin{tabular}{lllll}
\hline Insect & Site & \multicolumn{2}{c}{$\%$ Damaged $(N)$} & \multirow{2}{*}{$p^{\mathrm{a}}$} \\
\cline { 3 - 4 } & & Attached & Aborted & \\
\hline C. thomasi & Key Largo 1 & $42(152)$ & $61(36)$ & 0.0305 \\
C. thomasi & Key Largo 2 & $30(166)$ & $91(23)$ & $<0.0001$ \\
C. thomasi & Plantation Key 1 & $13(24)$ & $49(57)$ & 0.0015 \\
C. thomasi & Plantation Key 2 & $75(91)$ & $76(45)$ & $\mathrm{ns}$ \\
C. simaethis & Key Largo 3 & $37(75)$ & $13(15)$ & 0.0616 \\
C. simaethis & Plantation Key 3 & $45(95)$ & $10(10)$ & 0.0296 \\
L. flava & Key Largo 1 & $32(152)$ & $3(36)$ & $<0.0001$ \\
L. flava & Key Largo 4 & $25(44)$ & $0(10)$ & 0.0801 \\
\hline
\end{tabular}

${ }^{\text {a }}$ Fisher's exact one-tailed test.

Incidence of seed predators in sites exposed to mosquito spraying and other roadside disturbance vs. more protected sites: late 1980 s

In 1988 and 1989 we compared the incidence of seed predators on balloon vines in protected vs. exposed sites (Figure 3). Neither soapberry bugs, which were present at all sites in both years, nor the tortricid moth, which was found only at two protected and one exposed site in the first year, are graphed. The Miami blue was nearly absent from exposed sites, and the wasp completely so. In contrast, the silver-banded hairstreak was equally common in both. Overall, a much higher proportion of capsules were attacked in protected sites than exposed sites (combining the two lycaenids, instances when the two species were not distinguished, and wasps: Mean $\pm s d$ percentage at protected $=44.4 \pm 30.2$, exposed $=11.9 \pm 11.3$, $z=3.6, p<0.0003)$.

\section{Balloon vine fates and incidence of seed predators,} 1988-2003

Figure 4 diagnoses the fates of 32 fruiting balloon vines studied in 1988 and 1989 that were reassessed in 2003. Comparable ecological information is given for an additional 40 individuals new to the study in 2003. Of the historic vines, only one survived the 15 -year interim. Of the 24 that vanished, three-quarters were in sites showing evidence of human disturbance (detailed below). Seven other individuals had descendents as replacements. Half of the remaining or descended vines were physically disturbed. In contrast to the original 32 vines, only three descendant vines were fruiting. Seed predators were present on two of these: the silverbanded hairstreak and soapberry bug on one, and the tortricid moth on the other. No Miami blues or wasps were observed.

The group of 40 'New' plants consisted of individuals judged large enough to be reproductive. Of 
Table 7. Influence of experimental piercing and sealing of the capsule wall on the probability of abortion of immature and mature balloon vine fruits.

\begin{tabular}{|c|c|c|c|c|c|c|}
\hline \multirow[t]{2}{*}{ Site } & \multicolumn{3}{|c|}{ Immature capsules aborted $\%$} & \multicolumn{3}{|c|}{ Mature capsules aborted $(\%)$} \\
\hline & Pierced & Pierced and sealed & Untreated & Pierced & Pierced and sealed & Untreated \\
\hline 1 & $23(92)$ & $9(36)$ & $5(20)$ & $5(36)$ & $2(13)$ & $1(7)$ \\
\hline 2 & $8(80)$ & $3(30)$ & $1(10)$ & $5(50)$ & $1(10)$ & $2(2)$ \\
\hline 3 & $13(87)$ & $2(13)$ & $0(0)$ & $4(27)$ & $2(13)$ & $0(0)$ \\
\hline 4 & $25(100)$ & $6(24)$ & $2(8)$ & $10(40)$ & $4(16)$ & $4(16)$ \\
\hline Mean $\%$ & $90 \pm 8$ & $26 \pm 10$ & $9.5 \pm 8$ & $38 \pm 10$ & $13 \pm 2$ & $6 \pm 7$ \\
\hline & $\mathrm{a}$ & $\mathrm{b}$ & $\mathrm{c}$ & $\mathrm{b}$ & $\mathrm{c}$ & $\mathrm{c}$ \\
\hline
\end{tabular}

Analyses are for pooled plants; different letters denote Fisher's two-tailed exact probabilities of $<0.05$.

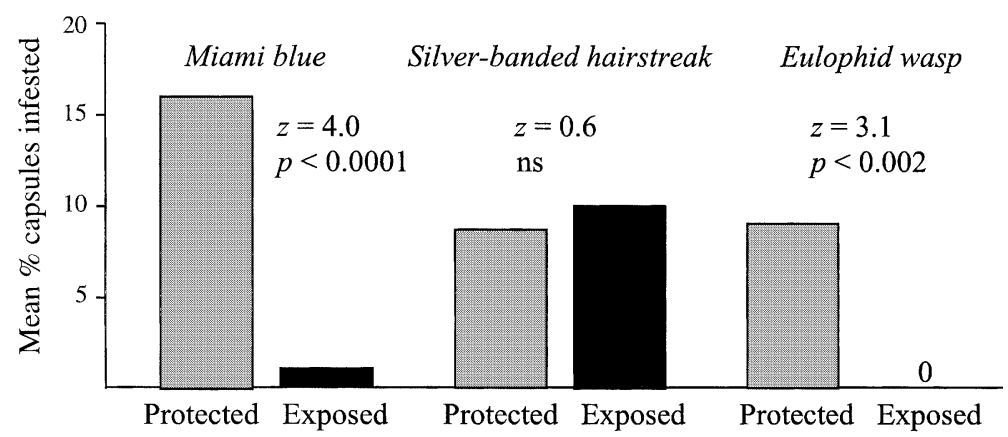

Figure 3. Mean percentage of capsules infested by the Miami blue, the silver-banded hairstreak, and the Eulophid wasp at two types of sites (1988 and 1989 pooled). 'Protected' sites $(N=18)$ were more than $50 \mathrm{~m}$ distant from roadside activities, including mosquito spraying, while 'exposed' sites $(N=22)$ were within $10 \mathrm{~m}$ of roadsides; $z$-values are from Wilcoxon Rank-sum statistics. The total number of balloons sampled in exposed sites (1988: $N=1238,1989: N=542$ ) was similar to that in protected sites (1988: $N=1216,1989: N=698$ ) (above).

these, one-third showed evidence of disturbance. As on the historic plants, we found no blues or wasps. Soapberry bugs and hairstreaks occurred in frequencies similar to those in 1988 and 1989. The hairstreaks appeared to be more common on undisturbed ('Intact') vines, but not significantly so (historic and new vines pooled, Fishers exact onetailed $p=0.11)$. In kind, disturbed plants were less likely to be fruiting, though this again was not statistically significant (historic and new vines pooled, Fisher's exact one-tailed $p=0.17$ ).

Of the 16 missing 'historic' vines with evident disturbance, six had occupied sites now annexed by expanded clearing for public roadside maintenance, four had been replaced by building or paving, four by landscaping or dumping, and two by introduced exotic vines. All three disturbed extant descendant plants had substantial physical damage from roadside clearing, as did the single long-term survivor. The pattern of disturbance in 'new' plants was similar: nine from roadside maintenance, and four cut for development.

\section{Discussion}

The geographic range of the Miami blue has diminished greatly over the past half century. In the 1980s and 1990s, it persisted along with other specialist insects on a disturbed population of balloon vine in the Upper Florida Keys. From a conservation standpoint, the most important events of the last few decades were the arrival of the silver-banded hairstreak and the high mortality and physical disturbance of mature balloon vines by civic maintenance and private development activities. Potentially positive changes in mosquito control practices also occurred during this period (below). Clearly, however, the overall reduction in the geographic range of the Miami blue increases its risk of decimation by local environmental 


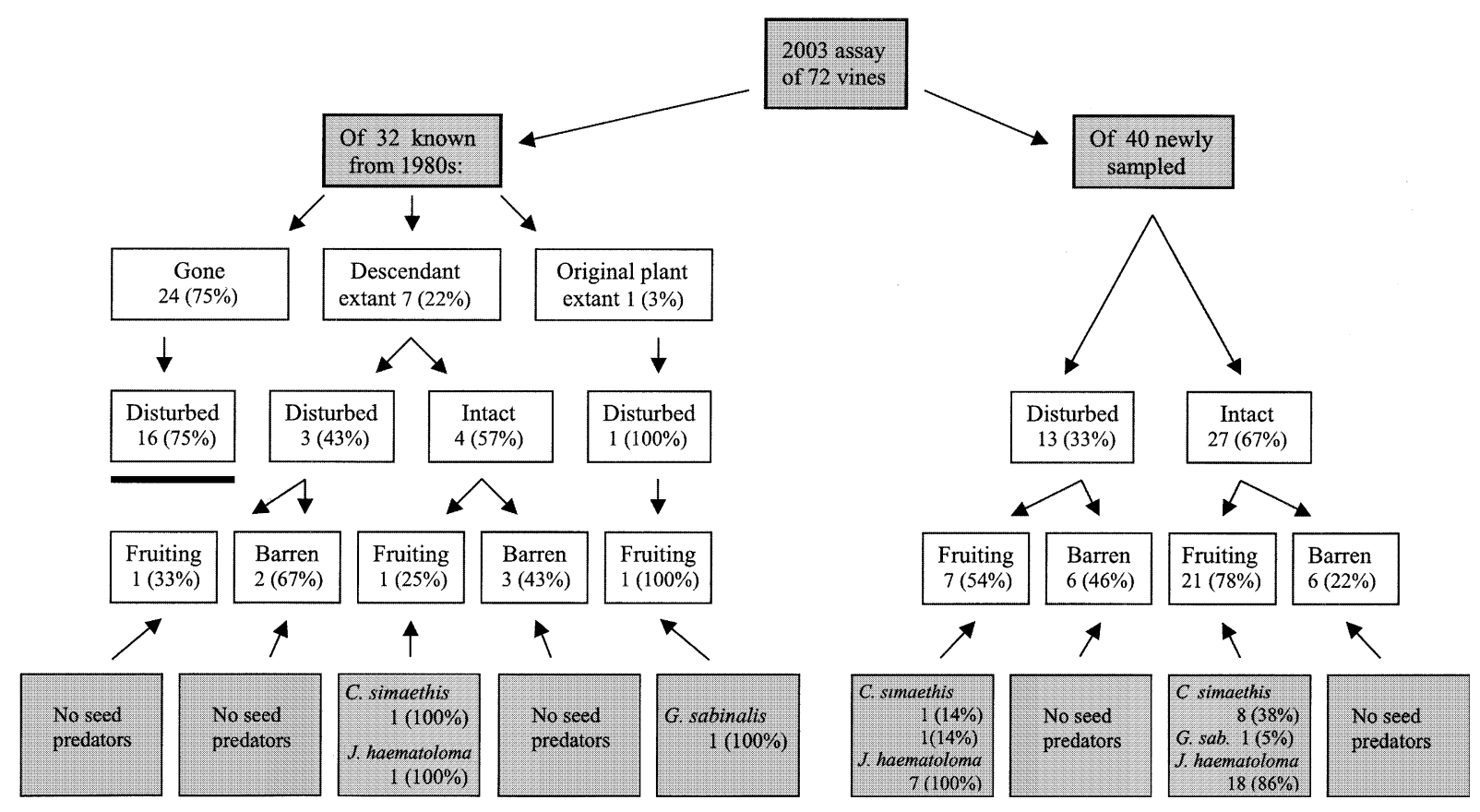

Figure 4. Fates and condition of 32 balloon vines between 1988 and 2003 (left), and condition of 40 additional vines first sampled in 2003 (right), along with the incidence of seed predators on them in 2003.

catastrophes including urban development (e.g., Arnold 1986; Mattoni 1989) and tropical storms (Emmel and Minno 1993).

We found close correspondence between the geographic decline of the balloon vine and the Miami blue during the 20th century. Populations of both species distant from their density nexus in the Upper Keys disappeared earlier than did more proximate populations. Rather than an exotic serving fortuitously as a "bridging" host during the decline of the Miami blue's greater coastal habitat (sensu Calhoun et al. 2002), the balloon vine is instead a declining native on which the butterfly has been largely dependent. Most of this decline on the mainland took place before colonization by the hairstreak. Such former Miami blue populations were likely accompanied by soapberry bugs (Carroll and Boyd 1992), but the distributional history of the wasp is little known. We found that the insect guild may kill a large proportion of seeds, though this likely varies and its impact on plant recruitment is not known. We noted that young $C$. corindum were reasonably common in North Key Largo in our 2003 surveys.

Interactions between the seed predators on balloon vine likely influenced food availability to the Miami blue. Both the blue and the wasp were nearly absent from sites in which the hairstreak was common. Co-occurrence was mediated both by oviposition decisions and larval behavior. Distributing eggs evenly among host resources has been reported in other Lepidoptera and may function to reduce the probability of larval competition (Shapiro 1981) and enhance access to larval resources. Conspecific egg recognition has been demonstrated in other butterflies (e.g., Rausher 1979; Rhainds 1996). We found evidence of similar behavior in the hairstreak as well as the wasp. The Miami blue showed less discrimination against ovipositing on capsules already bearing eggs, although we found no capsules with more than two eggs. The very low frequency of capsules with eggs of both butterfly species could be an effect, rather than a cause, of the two species' infrequent co-occurrence within sites.

More rapid larval development in hairstreaks may allow them to out-compete other larvae in patches where seeds are limiting. Such a developmental advantage would contribute to the disassociative relationship between the hairstreak and the other two species using immature seeds. In addition, in captive larvae we have observed both 
cannibalism among hairstreaks and predation of wasp larvae by Miami blues (Carroll and Loye, unpublished data). In theory, ant attendance of blue larvae could mediate such interactions between the species (sensu Pierce 1987). However, ant attendance was uncommon during our study period, and captive blue larvae and pupae completed development in their absence.

Plant response varied widely among the seed predators. Larval Miami blues stimulated capsule abortion, which they partially overcame by abandoning balloons in sequence. Abortion was far less common in fruits attacked by silver-banded hairstreaks, and our experiments suggested that this may result from their patching of the balloon wall. Wasp-infested fruits were not selectively aborted, and the galling of the seeds suggests chemical manipulation of the host.

Eulophid wasps are typically parasitoids of larval insects, and their presence on a plant host was unexpected. We lack observational data on their behavior due to their small size. However, the extreme female bias in sex ratio within fruits is probably an evolved product of local mate competition ensuing from eclosed siblings mating within capsules (Hamilton 1967). Mating may be followed by dispersal of fertilized females to new capsules when natal capsules dehisce. Groups with more females also had more males, but not so many additional as to suggest that hyperparasitism by additional foundresses is common (sensu Charnov 1982). In other words, like the two lycaenids, it appears that female wasps prefer to oviposit in a manner that isolates their young from conspecifics. Their relatively early oviposition on young balloons may give them little opportunity to avoid butterfly competitors or predators through strategic oviposition, however. On the other hand, we did not observe butterfly larvae eating galled seeds.

The geographic decline of the Miami blue included a period of relatively static rarity on Big Pine Key in the Lower Keys. Calhoun et al. (2002) indicate that balloon vine is present but not common on Big Pine Key, although we did not find it in our surveys, nor was it recorded by Dickson et al. in their floral survey of Big Pine Key (1953), Thus these insects appear to have persisted in a setting in which balloon vine was absent or nearly absent, but in which the 'secondary' host genera Caesalpinia and Pithecellobium are relatively common. With the blue currently limited to Caesalpinia bonduc on adjacent Bahia Honda Key, is should be considered that this population is the scion of a group historically segregated from the Upper Keys population associated with balloon vine.

The silver-banded hairstreak invaded the Upper Keys during a period when mosquito control spraying was active and widespread, and included aerial spraying of the north Key Largo wild areas until 1983 (M. Spoto, FKMCD, pers. comm. 2003). Our data indicate that the hairstreak was relatively resilient in exposed, roadside sites. Patching of entrance holes in balloons may provide some shelter from pesticides not enjoyed by the blue. Nonetheless, the hairstreak's range has declined over the past 15 years. Removal of mature host plants is the most evident source of habitat deterioration in our study. Ninety-six percent of the fruiting balloon vines in our Plantation Key transect disappeared during this period, and comparably productive individuals have not replaced them. We found no balloon vine on adjacent south Key Largo in 2003. Balloon vine is more common in north Key Largo, but again large individuals are infrequent.

In general, little is known about the effects of mosquito control spraying on butterflies or other invertebrates (reviewed by Lawler et al. 1999). For aerial spraying, the FKMCD has employed Naled (Dibrome) for many years, in ultra-low volume delivery since 1994. Truck-based fogging is with piperonyl butoxide catalyzed permethrins (Clarke 'Biomist 30 + 30 ULV'; M. Spoto, FKMCD pers. comm. 2003). Biomist is promoted as an "environmental' solution because of low toxicity to vertebrates and aquatic systems. However, the US EPA registrations of the main ingredients of both of these pesticides permit labeling for the control of lepidopterous pests of several families. Furthermore, an assessment of drift from Florida Keys aerial spraying operations showed significant contamination up to $750 \mathrm{~m}$ into protected areas (Hennessey et al. 1992). Little drift, in contrast, was associated with truck-based fogging. The ultra-low volume aerial spraying adopted subsequent to that study might reduce the material reaching nontarget areas.

Detailed studies of pesticide effects on butterflies are those conducted by students of Florida systems. Eliazar and Emmel (1991) and Eliazar 
(1992) found high adult toxicity of permethrin to a papilionid and a nymphalid and Salvato (2001) reported similar results for other adult and juvenile nymphalids and a lycaenid. Nonetheless, deleterious impacts of mosquito spraying on butterflies have been difficult to establish (Pyle 1976; Dover 1996). Emmel and Tucker (1991) found strong correlations between annual variation in spraying and the population size of an endangered Keys swallowtail. Salvato (2001) found a threatened Lower Keys nymphalid to be less common in sprayed areas, but a threatened lycaenid was consistently more common in the same sprayed areas. Salvato (2001) points to other environmental factors, in particular dry conditions that led to a decline in both host quality and mosquito spraying frequency, as important components of butterfly population regulation. Smith (2002) reached similar conclusions about the importance of seasonal and biotic factors from studying yet another endangered lycaenid in south Florida.

Declining lycaenid butterflies with specialized plant or ant dependencies have been the subjects of conservation analyses and restoration schemes for over 20 years (e.g., Arnold 1983; New 1993, 1997; Smith 2002). Habitat destruction associated with urban and suburban development is a common theme in such studies. Often depending on a particular plant species, the population of which is inherently small for reasons that may or may not be directly anthropogenic, the insects become acutely threatened when specific developments further degrade the host (Cushman and Murphy 1993). Such development may also reduce nectar sources for adults. Pesticides (Dover et al. 1990) and pollutants (Heath 1981) may be important as well, although direct causation is often uncertain (New, 1997).

For the Miami blue, the persistence (or appearance) of a reproducing population on nickerbean is a boon to its conservation (Daniels and Enamel 2004). Captive breeding programs should also carefully assess and perhaps promote its performance on balloon vine. In addition, as mandated by the Miami Blue Management Plan (Florida Fish and Wildlife Conservation Commission 2003) conservationists should collaborate with the FKMCD to better understand and manage nontarget effects. Such an initiative should include toxicological studies relevant to the District's highly modernized application methods, and the monitoring of both common and threatened species for short and long term response to pesticide application and drift. Collaboration between insect ecologists and mosquito control biologists is doubly important with the small populations and extraordinarily dynamic natural environment of the Florida Keys (sensu Davis 1965; Diamond 1984). Doing so will improve the possibility of conserving endangered biotic interactions (Dingle et a1. 1997) like the remarkably diverse guild of seed predators on balloon vine, rather than just some of the constituent species. Districts home to such small, specialized populations may economize with integrated long term planning that averts the need for frequent emergency measures. Other endangered butterflies are the recipients of expensive programs involving the purchase of habitat, the cessation of development, removal of invasive plants, the building of artificial nest boxes for associated ants, and the employment of specialized rangers (New 1997). While the extreme rarity of the Miami blue calls for intensive management, interagency cooperation, public involvement and comprehensive conservation planning in the Keys as a whole might mitigate the need for independent actions of this type for a multitude of species.

\section{Acknowledgements}

For sharing their expertise in Florida butterflies and their conservation we are very grateful to $\mathrm{T}$. Emmel, M. Minno and J. Daniels and P. Eliazar (all of the University of Florida). E. Fussell, Director, and M. Spoto, Superintendent of the Florida Keys Mosquito Control District (FKMCD) provided logistic support in 2003 including helicopter surveys and personnel. For assisting in fieldwork we thank L. Hribar, D. DeMay, B. Hovanich (all of FKMCD). R. DePalma (FKMCD) assisted with GPS work. Science educator H. Zim provided advice, housing and lab space on Plantation Key during fieldwork in the 1980s. Similar assistance was provided by the National Audubon Society's Plantation Key Research Office, particularly S. and D. Sprunt. R. Baranowski (Florida Department of Plant Industries, Homestead) originally introduced us to the plant C. corindum. We were generously assisted in herbarium work by K. Perkins (University of Florida), 
D. Correll of Fairchild Tropical Gardens, and R. Wunderlin (University of South Florida). J. Heppner (Florida State Arthropod Collection) identified the tortricid and along with $\mathrm{J}$. and $\mathrm{D}$. Miller (Allyn Museum) facilitated our museum studies of insects. J. LaSalle (now of CSIRO, Canberra) identified the wasp. NSF, NIH, the University of Utah, FKMCD, the Animal Behavior Society, and the American Museum of Natural History provided funding. Two anonymous reviewers improved the quality of the manuscript.

\section{References}

Arnold R.A. 1983. Ecological studies of six endangered butterflies (Lepidoptera: Lycaenidae): island biogeography, patch dynamics and the design of habitat preserves. Univ. Calif. Publ. Entomol. 99: 1-161.

Arnold R.A. 1986. Decline of the endangered Palos Verdes blue butterfly in California. Biol. Conserv. 40: 203-217.

Calhoun J.V., Slotten J.R. and Salvato M.H. 2002. The rise and fall of tropical blues in Florida: Cyclargus ammon and $C y$ clargus thomasi bethunebakeri (Lepidoptera: Lycaenidae). Holarctic Lepidoptera 7: 13-20.

Carroll S.P. and Boyd C. 1992. Host race radiation in the soapberry bug: Natural history, with the history. Evolution 46: 1052-1069.

Carroll S.P., Dingle H. and Klassen S.P. 1998. Rapidly evolving adaptations to host ecology and nutrition in the soapberry bug. Evol. Ecol. 12: 955-968.

Carroll S.P. and Loye LE. 1987. Specialization of Jadera species (Hemiptera: Rhopalidae) on seeds of the Sapindaceae, and coevolution of defense and attack. Annl Entomol. Soc. Am. 80: $373-378$

Carroll S.P., Marler M., Winchell R. and Dingle H. 2003. Evolution of cryptic flight morph and life history differences during host race radiation in the soapberry bug (Jadera haematoloma) (Hemiptera: Rhopalidae). Annl. Entomol. Soc. Am. 96: 135-143.

Charnov E.L. 1982. The Theory of Sex Allocation. Princeton University Press, Princeton.

Cushman J.H. and Murphy D.D. 1993. Conservation of North American lycaenids-an overview. In: New T.R. (ed.), Conservation Biology of the Lycaenidae. IUCN, Gland, pp. 37-44.

Daniels J.C. and Emmel T.C. 2004. Florida's precious Miami blues. Wings 27: 3-7.

Davis B.N.K. 1965. Pesticides and wildlife conservation. J. Entomol. Soc. Aust. (NSW) 2: 1-7.

Diamond J.M. 1984. "Normal" extinctions of isolated populations. In: Nitecki M.H. (ed.), Extinctions. University of Chicago Press, Chicago, pp. 193-246.

Dickson J.D.III, Woodbury R.O. and Alexander T.R. 1953. Check list of flora of Big Pine Key, Florida, and surrounding keys. Quarter. J. Florida Acad. Sci. 16: 181-197.

Dingle H., Carroll S.P. and Loye J. 1997. Behavior, conservation and $99 \%$ of the world's biodiversity: Is our ignorance really bliss?. In: Clemmons J. and Buckholz R. (Eds.), in Behavioral Approaches to Conservation in the Wild. Oxford, Oxford University Press, pp. 72-92.

Dover J.W. 1996. Factors affecting the distribution of satyrid butterflies on arable farmland. J. Appl. Ecol. 33: 723-734.

Dover J.W., Sotherton N. and Gobbett K. 1990. Reduced pesticide inputs on cereal field margins: the effects on butterfly abundance. Ecol. Entomol. 15: 17-24.

Eliazar P.J. and Emmel T.C. 1991. Adverse impacts to nontarget insects. In Emmel T.C. and Tucker J.C. (Eds.), Mosquito Control Pesticides: Ecological Impacts and Management Alternatives. Conference Proceedings. Scientific Publishers Inc., Gainesville, Florida, pp. 17-19.

Eliazar P.J. 1992. Impact of two mosquito adulticides, naled and fenthion, on selected nontarget lepidopteran species. University of Florida, Gainesville, pp. 57 MS thesis.

Emmel T.C. and Minno M.C. 1993. The Atala butterfly, Eumaeus atala florida (Röber)'. In: New T.R. (Ed.), Conservation Biology of the Lycaenidae. IUCN, Gland, pp. 129-130.

Emmel T.C. and Tucker J.C. 1991. Mosquito Control Pesticide: Ecological Impacts and Management Alternatives. Scientific Publishers, Gainesville, pp. 105

Emmel T.C. and Daniels J.C. 2003. Captive propagation and reintroduction plan for the Miami blue butterfly (Hemiargus[Cyclargus] thomasi bethunebakeri). McGuire Center for Lepidoptera Research, University of Florida, GainesvilleDraft plan submitted to the Florida Fish and Wildlife Conservation Commission and the U.S. Fish and Wildlife Service, July 18, 2003.

Fisher M.S. 1974. Two new Thecla from the continental United States (Lycaenidae). J. Lepidopterist's Soc. 28: 305.

Fisher M.S. 1975. A correction. J. Lepidopterists' Soc. 29: 127.

Florida Administrative Code 1975. Sections 28-29. State of Florida, Tallahassee, Florida.

Florida Fish and Wildlife Conservation Commission 2003. Final biological status report - Miami blue. State of Florida, Tallahassee, Florida.

Hamilton W.D. 1967. Extraordinary sex ratios. Science 156: 477-488.

Heath J. 1981. Threatened Rhopalocera (Butterflies) of Europe. Council of Europe, Strasbourg.

Hennessey M.K., Nigg H.N. and Habeck D.H. 1992. Mosquito (Diptera: Culicidae) adulticide drift in wildlife refuges of the Florida Keys. Environ. Entomol. 21: 714-721.

Lawler S.P., Jensen T., Dritz D.A. and Wichterman G. 1999. Field efficacy and nontarget effects of the mosquito larvicides temephos, methoprene, and Bacillus thuringiensis var. israelensis in Florida mangrove swamps. J. Am. Mosq. Control Assoc. 15: 446-452.

Lenczewski B. 1980. Butterflies of Everglades National Park. National Park Service Everglades, National Park Homestead, Florida.

Leston D., Smith D.S. and Lenczewski B. 1982. Habitat diversity and immigration in a tropical island fauna: the butterflies of Lignum Vitae Key, Florida. J. Lepidopterists' Soc. 36: $241-255$.

Loye J.E. and Carroll S.P. in press A plant piñata: seed predation on the balloon vine by the Miami blue silver-banded hairstreak a eulophid wasp and the soapberry bug in the Florida Keys. Holarctic Lepidoptera. 
Mattoni R. 1989. Conflict and conservation: the El Segundo blue (Lycaenidae) and the airport. Nota Lepidoptera 12: 12 .

Minno M.C. and Emmel T.C. 1993. Butterflies of the Florida Keys. Scientific Publishers, Gainesville, Florida.

Monroe County 1995. Monroe County Year 2010 Comprehensive Plan. Technical Document. Monroe County Planning Department Key West, Florida.

Monroe County 2002. Key Deer Habitat Conservation Plan. Monroe County Board of County Commissioners, Key West, Florida.

New T.R. 1993. Editor Conservation Biology of the Lycaenidae. IUCN, Gland.

New T.R. 1997. Butterfly Conservation, 2nd ed. Oxford University Press, Oxford.

Opler P.A. and Krizek G.O. 1984. Butterflies east of the Great Plains. Johns Hopkins University Press, Baltimore.

Pierce N.E. 1987. The evolution and biogeography of association between lycaenid butterflies and ants. Oxford Surveys Evol. Biol. 4: 89-116.

Pyle R.M. 1976. Conservation of Lepidoptera in the United States. Biol. Conserv. 9: 55-75.

Rausher M.D. 1979. Egg recognition: its advantage to a butterfly. Animal Behav. 27: 1034-1040.
Rhainds M., Gries G. and Morales J.L. 1996. Oviposition deterrency in pineapple borer females, Thecla basilides (Lepidoptera: Lycaenidae). Ecol. Entomol. 21: 105-106.

Salvato M.H. 2001. Influence of mosquito control chemicals on butterflies (Nymphalidae, Lycaenidae, Hesperiidae) of the lower Florida Keys. J. Lepidopterists' Soc. 55: 8-14.

Shapiro A.M. 1981. The pierid red-egg syndrome. Am. Nat. 117: $276-294$

Small J.K. 1933. Manual of the Southeastern Flora. University of North Carolina Press, Chapel Hill.

Smith D., Miller J. and Miller L. 1994. The Butterflies of the West Indies and South Florida. Oxford University Press, Oxford.

Smith E.M. 2002. The effects of season, host plant protection, and ant predators on the survival of Eumaeus atala (Lycaenidae) in re-establishments. J. Lepidopterist's Soc. 56: $272-276$.

Strong A.M. and Bancroft G.T. 1994. Patterns of deforestation and fragmentation of mangrove and deciduous seasonal forests in the Upper Florida Keys. Bull. Marine Sci. 54: 795-804.

Tomlinson P.B. 1980. Trees Native to Tropical Florida. Harvard University Printing Office, Allston Massachusetts.

Wunderlin R.P. 1998. Guide to the Vascular Plants of Florida. University of Florida Press, Gainesville, Florida. 